\title{
Effect of Environment and Sugar Beet Genotype on Root Rot Development and Pathogen Profile During Storage
}

\author{
Sebastian Liebe and Mark Varrelmann
}

Institute of Sugar Beet Research Holtenser Landstr. 77, 37079 Göttingen, Germany. Accepted for publication 9 October 2015.

\begin{abstract}
Liebe, S., and Varrelmann, M. 2016. Effect of environment and sugar beet genotype on root rot development and pathogen profile during storage. Phytopathology 106:65-75.

Storage rots represent an economically important factor impairing the storability of sugar beet by increasing sucrose losses and invert sugar content. Understanding the development of disease management strategies, knowledge about major storage pathogens, and factors influencing their occurrence is crucial. In comprehensive storage trials conducted under controlled conditions, the effects of environment and genotype on rot development and associated quality changes were investigated. Prevalent species involved in rot development were identified by a newly developed

microarray. The strongest effect on rot development was assigned to environment factors followed by genotypic effects. Despite large variation in rot severity (sample range 0 to $84 \%$ ), the spectrum of microorganisms colonizing sugar beet remained fairly constant across all treatments with dominant species belonging to the fungal genera Botrytis, Fusarium, and Penicillium. The intensity of microbial tissue necrotization was strongly correlated with sucrose losses $\left(R^{2}=0.79\right.$ to 0.91$)$ and invert sugar accumulation $\left(R^{2}=0.91\right.$ to 0.95$)$. A storage rot resistance bioassay was developed that could successfully reproduce the genotype ranking observed in storage trials. Quantification of fungal biomass indicates that genetic resistance is based on a quantitative mechanism. Further work is required to understand the large environmental influence on rot development in sugar beet.
\end{abstract}

In Europe, the sugar beet root can undergoes a considerable postharvest period in storage within infield clamps for up to 80 days (Jaggard et al. 1997). The amount of recoverable white sugar from stored beets is largely affected by the processing quality which is greatest when roots contain a high concentration of sucrose and a low concentration of impurities. The major melassigenic substances, namely potassium, sodium and amino-nitrogen, lead to increased sucrose loss to molasses. In addition, invert sugars (glucose + fructose) promote color formation in extracted juice, reduce sugar crystallization and negatively affect filtration (Hoffmann 2010). Any increase in these impurities leads to a higher demand of energy and processing and decreases the efficiency of sugar recovery (Hoffmann 2010). Thus, the major goal for storage is to conserve the sugar that accumulated during the growing season and to prevent accumulation of impurities.

In general, storage of sugar beet is always accompanied by sucrose losses and accumulation of invert sugar. Jaggard et al. (1997) reported sugar yield losses between 0.018 to $0.143 \%$ per day accompanied by a fourfold increase in invert sugar. In principle, these losses and enzymatic conversions can be attributed either to plant respiration or microbial colonization accompanied by rot development. Losses caused by respiration are inherent and cannot be prevented. The development of storage rots is accompanied by the secretion of microbial derived sucrolytic enzymes (invertases) leading to a reduction of sucrose and accumulation of invert sugars (Klotz and Finger 2004). In a survey conducted over 128 days in the United States, $1.2 \%$ of all processed roots $(456,820$ tons) were affected by storage rots (Bugbee 1982). Consequently, direct sucrose losses during storage and losses due to processing problems in the factory, lead to approximately 1,315 tonnes of sucrose being lost due to these storage rots.

Corresponding author: M. Varrelmann;

E-mail address: varrelmann@ifz-goettingen.de

http://dx.doi.org/10.1094/PHYTO-07-15-0172-R

(C) 2016 The American Phytopathological Society
Usually, sugar beet subjected to storage possesses a high water (on average $76.1 \%$ ) and sugar content (on average 17.2\%) (Jaggard et al. 1997), providing ideal conditions for microbial growth. Additionally, severe injuries (e.g., bruising, cracks, and root tip breakage) caused by mechanical harvesting and topping constitute entry sites for wound pathogens which are unable to readily penetrate intact cell wall barriers of the periderm (Bugbee 1982; Wyse 1978a,b). Thus, apparently healthy harvested sugar beet can display rot symptoms after storage (Campbell and Klotz 2007; Christ et al. 2011). Frequently isolated species from deteriorated beets are Botrytis cinerea, Fusarium spp., Penicillium spp., and Phoma betae (Bosch and Mirocha 1992; Bugbee 1975; Bugbee and Cole 1976; Strausbaugh et al. 2015). Besides fungal organisms, storage rots have been also associated with colonization of bacterial species like Leuconostoc mesenteroides subsp. dextranicum (Strausbaugh et al. 2011; Tallgren et al. 1999). However, the current knowledge about the relative importance of microorganisms affecting sugar beet roots is based on a relatively few studies conducted solely in the United States where most sugar beets are cooled or, to a lesser degree, frozen during storage. Moreover, many studies did not classify any storage pathogens (Gaskill 1950a,b,c; Van Swaaij and Huijbregts 2010) or provided only little information on species involved (Klotz and Finger 2004; Strausbaugh et al. 2011). Thus little is known about the relative importance of the above mentioned species and their incidence in Europe. A recent study, focusing only on Fusarium spp., could identify up to twelve different species colonizing sugar beet when stored under controlled conditions for 16 weeks (Christ et al. 2011). This indicates a substantial postharvest microbial colonization which has not been investigated in detail previously.

Besides knowledge about predominant storage pathogens, a clear understanding of factors promoting their occurrence is crucial to develop management strategies that minimize microbial induced postharvest sucrose losses. Previous studies showed that the storability of sugar beet varies depending on cultivation practice (Campbell and Klotz 2007) and genotype (Akeson and Widner 1981; Campbell and Klotz 2007; Cole 1977; Kenter and Hoffmann 
2009; Van Swaaij and Huijbregts 2010; Wyse and Dexter 1971a,b). However, these studies focused primarily on sucrose loss and invert sugar accumulation without considering storage rots. As the quality of sugar beet is strongly impaired by rot development, a precise quantification of its severity is necessary to understand the factors that determine the variability of sugar beet storability. By weighing the rotten tissue, Gaskill (1950b) was able to show that genotypes differ in their susceptibility toward storage pathogens. Furthermore evidence suggests that the environment of cultivation also has an influence on storage rot development (Bugbee and Cole 1986). However, studies addressing the combined effect of environment and genotype on storage rot severity, storage pathogens involved and associated quality changes are missing. Therefore, comprehensive storage and greenhouse trials were conducted in this study to investigate the influence of both environment and genotype on storage rots. A recently developed microarray containing 42 probes enabling the identification of prevalent field pathogens (e.g., Aphanomyces cochlioides), storage pathogens (e.g., Botrytis cinerea), and ubiquitous spoilage fungi (e.g., Penicillium expansum) (Liebe et al. 2016) was applied to study changes in the microbial community during storage. Based on a comparative analysis of sugar beets displaying low and severe rot symptoms, major species associated with rot development were identified.

\section{MATERIALS AND METHODS}

Cultivation of beet, harvest, and storage trials. Three sugar beet genotypes (hybrids), namely A (Code: KWS06, KWS Saat AG, Einbeck, Germany), B (Code: STR11, Strube Research, Schlanstedt, Germany) and C (Code: SYN25, Syngenta Seeds, Landskrona, Sweden), were sown at five (2011) and four (2012, 2013) different environments in Lower Saxony, North RhineWestphalia and Saxony (Table 1). The selected locations did not show any infestation with soilborne diseases or nematodes over the last decade. Sugar beet genotypes were cultivated in a randomized block design applying standard agronomical practices and pesticide spraying following recommendations of the local extension service. Mechanical harvest including topping was conducted at the beginning of October in each year with two exceptions. In environments 5 and 9 (Table 1), sugar beets were topped and hand-harvested. After harvest, all sugar beets belonging to the same genotype but cultivated in different plots were thoroughly mixed and poorly topped and damaged beets were removed.

Three storage trials were performed between 2011 and 2013 (Table 1). The effect of genotype and environment on the development of storage rots was evaluated in every year. In 2013, an additional damage treatment was integrated prior to storage to promote rot development. For this purpose, sugar beets were injured after harvest by tumbling in a cleaning drum for $45 \mathrm{~s}$ as described by Kenter et al. (2006). All treatments consisted of five (2011) or six (2012 and 2013) replicates comprised of 20 roots were placed in nylon potato bags $(50 \times 80 \mathrm{~cm}$, Raiffeisen Warenhandel $\mathrm{GmbH}$, Rosdorf, Germany). Each sample was weighed and then stored

TABLE 1. Overview of sugar beet storage trials performed between 2011 to 2013

\begin{tabular}{lllc}
\hline Year & Treatment $^{\mathrm{a}}$ & \multicolumn{1}{c}{ Treatment level $^{\mathrm{a}}$} & Storage duration \\
\hline 2011 & Genotype & $\mathrm{A}^{*}, \mathrm{~B}^{*}, \mathrm{C}^{*}$ & 103 days \\
& Environment & $1^{*}, 2,3,4,5^{*}$ & 91 days \\
2012 & Genotype & $\mathrm{A}^{*}, \mathrm{~B} *, \mathrm{C}^{*}$ & \\
& Environment & $6^{*}, 7,8,9^{*}$ & 97 days \\
2013 & Genotype & $\mathrm{A}^{*}, \mathrm{~B}^{*}, \mathrm{C}^{*}$ & \\
& Environment & $1^{*}, 11^{*}, 12$ & \\
& Damage & Undamaged ${ }^{*}$ and damaged* & \\
\hline
\end{tabular}

\footnotetext{
${ }^{a}$ Environment numbers indicate different cultivation sites of sugar beets. * Indicates treatments were selected for microarray analysis before and after storage.
}

under controlled conditions $\left(8^{\circ} \mathrm{C}\right)$ for either 103 days (2011), 91 days (2012), or 97 days (2013) in cool containers (Conrail, Hamburg, Germany). Relative humidity within containers was $100 \%$. To determine the quality of sugar beet prior to storage, five (2011) or six (2012 and 2013) reference samples (20 roots) per treatment were taken and immediately subjected to quality analysis.

Storage rot rating and quality analysis. After storage, samples were weighed again and each beet was cut longitudinally into two. The amount of discolored (rotted) tissue visible in the longitudinal cut of one half was estimated using a percentage scale between 0 and $100 \%$ (storage rot severity). Subsequently, beets were washed and processed to produce brei samples and rapidly frozen at $-80^{\circ} \mathrm{C}$. Brei was clarified with $0.3 \%$ aluminum sulfate solution and filtrates were used to determine potassium, sodium and amino $\mathrm{N}$ in an automatic beet laboratory system (Venema, Groningen, The Netherlands) according to standard protocols (Burba and Georgi 1975, 1976; International Commission for Uniform Methods of Sugar Analysis 2003). Normally, the sucrose concentration in sugar beet is measured polarimetrically. However, nonsugar substances, if present in high concentrations in severely infected beets, interfere with the polarimetric measurement. Therefore, the sucrose concentration was determined in the filtrates using the resorcinol method from Roe (1934) which is based on a colorimetric measurement $(490 \mathrm{~nm})$ of sucrose. The measurement is not impaired by a high concentration of nonsugar substances. Before and after storage, the white sugar yield (WSY) was estimated for each sample using the formula: sample weight $\times($ sucrose $\%-$ SMV - SFL $) / 100$. SMV stands for standard molasses loss (\%) according to Buchholz et al. (1995) and SFL for standard factory loss (6\%). To determine the initial WSY, the average sucrose concentration determined in the reference samples was applied to the formula. Finally, the WSY after storage was related to the initial WSY and expressed in percentage WSY reduction. The concentration of invert sugar was also analyzed in each filtrate according to the Somogyi-Nelson method (Nelson 1944; Somogyi 1945). Determination of invert sugar using this method is based on the absorbance $(540 \mathrm{~nm})$ of a colored complex between a copper oxidized sugar and arsenomolybdate.

Detection of storage rot pathogens. A recently developed microarray (Liebe et al. 2016) was applied to identify predominant species colonizing stored sugar beet. Sugar beet brei was used for sampling as it constitutes a homogenous mixture produced from 20 beets. For this purpose, brei samples were rapidly frozen in liquid nitrogen and then stored at $-20^{\circ} \mathrm{C}$. Treatments selected for microarray detection before and after storage are indicated in Table 1. For stored sugar beets, two replicates from each treatment were analyzed leading to 12 (2011 and 2012) and 24 (2013) samples in each year. In addition, two replicates from each treatment were taken before storage and analyzed as reference samples (12 in each year). DNA extraction, polymerase chain reaction (PCR), and microarray analysis was carried out according to Liebe et al. (2016).

Storage rot resistance assay. Sugar beet genotypes A and B were cultivated in the field (environment 12, 2013) and handharvested at the same time as the sugar beet for storage trials. Additionally, sugar beet of the same genotypes were grown in the greenhouse for 23 weeks according to Christ et al. (2011). At harvest, all beets either from field or greenhouse were manually topped, cleaned, and weighed. An isolate of $F$. graminearum obtained from a stored sugar beet (DSM23352, Deutsche Sammlung von Mikroorganismen und Zellkulturen, Braunschweig, Germany) was used for inoculation. Fungal cultures were grown on potato dextrose agar (Carl Roth, Karlsruhe, Germany) for 7 days at $25^{\circ} \mathrm{C}$ in the dark. Roots were prepared for inoculation by pulling a plug $(5 \mathrm{~mm}$ diameter, $10 \mathrm{~mm}$ depth) below the topped crown with a cork borer. An agar plug $(5 \mathrm{~mm} \times 5 \mathrm{~mm})$ taken from an actively growing culture was placed into each hole and the root plug was then put back to seal the hole. In total, 20 sugar beet roots of each genotype were inoculated with $F$. graminearum; five beets were mock-inoculated with PDA only. Roots were incubated in a climate chamber either for 21 days 
(greenhouse-grown beets) or 24 days (field-grown beets) at $20^{\circ} \mathrm{C}$ and $80 \%$ relative air humidity. After incubation, total root weight was determined and the necrotic tissue cut out and weighed separately. Subsequently, the entire root including both healthy and necrotic tissue was processed to produce a sugar beet brei that was subjected to quality analysis. Furthermore, brei samples, for the determination of fungal biomass were rapidly frozen in liquid nitrogen and stored at $-20^{\circ} \mathrm{C}$.

Quantification of fungal biomass. Approximately $100 \mathrm{mg}$ of brei produced from inoculated sugar beet was subjected to DNA extraction. The DNeasy Plant Mini Kit (Qiagen, Hilden, Germany) was applied for DNA extraction according to the manufacturer's protocol. After extraction, DNA was gel-checked for quality and quantified using a BioPhotometer (Eppendorf, Germany). Primers Fg16NF/Fg16NR were used to amplify a 280-bp product specific to $F$. graminearum (Nicholson et al. 1998). The function of this amplified genomic sequence is unknown as these primers were derived from randomly amplified genomic fragments. The reaction was set up in a $20 \mu \mathrm{l}$ volume containing $1 \times$ iTaq Universal SYBR Supermix (Bio-Rad), $10 \mu \mathrm{M}$ of each primer and $1 \mu \mathrm{l}$ of genomic DNA (1 ng/ $\mu$ l). The CFX96 Touch real-time PCR detection system (Bio-Rad) was used for amplification applying cycle conditions published by Brandfass and Karlovsky (2006). The standard curve was produced from a 10-fold serial dilution ( 7 to $0.007 \mathrm{ng} / \mu \mathrm{l})$ of purified total DNA from $F$. graminearum. Post PCR analysis of all amplification products was performed by creating a melting curve temperature profile between $75^{\circ} \mathrm{C}$ to $95^{\circ} \mathrm{C}$ with a slope of $0.2^{\circ} \mathrm{C}$ every $10 \mathrm{~s}$ and a continuous measurement of the fluorescence. Each sample was analyzed in duplicate and raw cycle threshold $\left(C_{t}\right)$ values were averaged. The concentration of fungal DNA in each sample was calculated using the regression function obtained from the standard curve. The amount of fungal biomass was finally expressed as nanogram $F$. graminearum DNA per gram of fresh matter (FM).

Data analysis. Statistical analysis was carried out with SAS Version 9.3 (SAS Institute Inc., Cary, NC). Storage trials conducted in different years were analyzed separately due to differences in storage duration and sample size. The MIXED procedure in SAS was used for analysis of variance (ANOVA). Residuals were tested for normality using the Kolmogorov-Smirnov test $(P<0.05)$, and if necessary, data were transformed to approximate normal distribution. Variance heterogeneity was considered by estimating different covariance parameter for each effect using the "GROUP=" syntax in SAS. Based on the Akaike information criterion (AIC), the bestfit model was selected and tested against the null model (one covariance) using the likelihood ratio test implemented in the MIXED procedure $(P \leq 0.05)$. All factors were considered fixed effects and tested for significance in the $F$ statistic $(P \leq 0.05)$. The denominator degrees of freedom for the tests of fixed effects were approximated according to the method of Kenward and Roger (1997). When factors or interactions were significant $(P<0.05)$, means were separated by the Tukey Kramer test $(P<0.05)$ using the macro PDMIX800 (Saxton 1998). Furthermore, regression analysis between storage rot severity and quality parameters was performed using the REG procedure to identify any correlations. The AIC and adjusted $R^{2}$ were used as criteria for selecting the best regression equation. Residuals were checked for normality using the KolmogorovSmirnov test $(P<0.05)$.

\section{RESULTS}

Storage trials 2011, 2012, and 2013. Storage trials conducted in 2011 and 2012 aimed to analyze the occurrence of sugar beet storage rots depending on genotype and environment. For this purpose, three genotypes were cultivated in different environments, stored under controlled conditions and assessed for rot severity after storage. In general, the amount of necrotic tissue could be easily evaluated as it was clearly distinguishable from the healthy tissue by its dark brown color. Rot symptoms were mostly restricted to the crown and tip of the root but in some cases it penetrated deep into the pith. The results of the ANOVA for each trial are summarized in Table 2. The main effects (genotype and environment) were significant $(P<0.0001)$ in both years with the strongest influence being the environment (2011: $F=176.4 ; 2012: F=190.8)$. Additionally, the environment-genotype interaction was also significant $(P<0.0001$ to 0.05$)$ all 3 years. Therefore, the interaction was considered during posthoc analysis (Fig. 1).

In 2011, beets from all genotypes in all environments displayed storage rots, but the severity varied considerably (sample range: 0.5 to $84.5 \%$ ) depending on the environment where the sugar beets had been cultivated. Hand-harvested sugar beets (environment 5) displayed the lowest rot severity (approximately 3\%). In contrast, sugar beets derived from environment 1 were most heavily affected by storage rots with an average value of $57.5 \%$. A clear differentiation between genotypes was only observed in certain environments ( 1 and 2$)$ as already indicated by the significant interaction. Genotype B ranked first in environment 1 (69.4\%) and 2 (39.6\%), but the differentiation was only significant from genotype A $(23.1 \%)$ in environment 2 . In contrast, no genotype differentiation was observed for sugar beet from environments 3,4 , and 5 .

The same effects could be observed in 2012, although the overall storage rot severity was considerably lower than in 2011 (sample range: 0 to $17.2 \%$ ). The ranking of genotypes, however, was consistent to the year before as genotype B displayed a significantly higher storage rot severity $(12.2 \%)$ than $\mathrm{A}(3.7 \%)$ and $\mathrm{C}(4.6 \%)$ in environment 7 . The identical ranking was observed for sugar beets derived from environment 6 , although it was only significant for the comparison between B (12.2\%) and C (6.1\%). Similar to 2011, hand-harvested sugar beets from environment $9(0.4 \%)$ were least affected by storage rots without genotype differentiation.

In 2013, sugar beet roots from field trials were further damaged mechanically prior to storage. It was aimed to increase the development of storage rots and to test if this treatment leads to enhanced genotypic differentiation. According to the ANOVA, the damage effect was highly significant, exerting the strongest effect on storage rot severity $(F=271.9)$ followed by genotype $(F=35.1)$ and environment effect $(F=15.3)$ (Table 2$)$. The interaction of all three main effects (damage-environment-genotype) was also significant and further analyzed (Fig. 2). Storage rot severity varied greatly depending on the treatment (sample range: 0.3 to $51.5 \%$ ). In general, mechanically damaged roots (overall mean $=29.3 \%$, standard deviation $=11.6$ ) displayed more severe storage rots than untreated ones (overall mean $=11.6 \%$, standard deviation $=8.3$ ) . Furthermore, ranking of genotypes was similar to the years before with genotype B displaying the highest storage rot severity. In environment 11, untreated sugar beet roots were least affected by storage rots (on average 6.4\%) without any genotype differentiation. However, following mechanical damage, the storage rot severity of

TABLE 2. Analysis of variance for effects of environment, genotype, and damage (percentage of sugar beet tissue rotted)

\begin{tabular}{llrc}
\hline Trial & \multicolumn{1}{c}{ Effect } & $F$ value & $P$ value \\
\hline 2011 & Environment & 176.4 & $* *$ \\
& Genotype & 16.1 & $* *$ \\
& Environment-genotype & 3.9 & $* *$ \\
\multirow{2}{*}{2011} & Environment & 190.8 & $* *$ \\
& Genotype & 10.9 & $* *$ \\
& Environment-genotype & 5.7 & $* *$ \\
& Damage & 271.9 & $* *$ \\
& Environment & 15.3 & $* *$ \\
& Genotype & 35.1 & $* *$ \\
& Damage-environment & 37.2 & $* *$ \\
& Damage-genotype & 7.2 & $* *$ \\
& Environment-genotype & 2.9 & $*$ \\
& Damage-environment-genotype & 5.5 & $* *$ \\
\hline
\end{tabular}

a Significance: $* *$ and $*=P<0.001$ and 0.05 , respectively. 
genotype B was highest (48.3\%) and differed significantly from genotype C (30.4\%). Sugar beets derived from environment 10 and 12 displayed in the untreated variants already a slight genotype differentiation which could be further pronounced after damaging but without statistical significance. The additional damage increased the overall rot severity in both environments without changing the ranking of genotype $\mathrm{B}$. In contrast, the ranking of genotypes $\mathrm{A}$ and $\mathrm{C}$ changed, but there was no significant differentiation between both genotypes.

Relationship between storage rot severity and quality parameters. To assess the effect of storage rots on the quality of sugar beets, reduction in WSY and invert sugar content were determined for each sample and plotted against the storage rot severity (Fig. 3). Independent of the genotype, an increase in the storage rot severity was accompanied by a dramatic reduction in WSY (sample range: 0.1 to $85.3 \%$ ) and high accumulation of invert sugar (sample range: 4.8 to $650.9 \mathrm{mmol} \mathrm{kg}-1$ of FM). The high coefficients of determination for all regression functions (ranging between 0.79 to 0.95 ) show that the variability in the reduction of WSY and invert sugar content can be mainly attributed to the varying storage rot severity. Additionally the strong association indicates that the ranking of genotypes and environments in storage rot severity was similar for both quality parameters (data not shown). For example, in environment 1 where sugar beets displayed the highest rot severity, WSY of genotype B was reduced by $74 \%$ and invert sugar content increased to $483 \mathrm{mmol} \mathrm{kg}-1$ of FM. In contrast, hand-harvested sugar beets with a low storage rot severity (environment 5) contained on average only $20 \mathrm{mmol} \mathrm{kg}-1$ of FM invert sugar with a minimal WSY reduction of $8.5 \%$. Furthermore, genotypes cultivated in environment 1 displayed a similar ranking in WSY reduction with $50.5 \%$ (A), 74\% (B), and 48\% (C) compared with the storage rot rating. However the slopes of all regression functions overlap in their confidence intervals, suggesting that the genotypes responded similarly to increasing storage rot severity (data not shown). This was also the case for the intercepts, meaning that all genotypes would display similar low amounts of invert sugar and WSY losses when storage rots are absent (data not shown).

Storage rot resistance bioassay. To find evidence whether the genotype effect observed in the storage trials could be reproduced with inoculation under laboratory conditions, sugar beet roots of genotype A and B were grown in the greenhouse (experiment I) as well as in the field (experiment II), and after harvest inoculated with $F$. graminearum. After incubation for either
21 days (experiment I) or 24 days (experiment II), the amount of necrotic tissue, invert sugar, and fungal biomass was determined (Table 3). In general, F. graminearum induced rots in roots of both genotypes whereas noninoculated roots remained unaffected. Genotype B was more susceptible than genotype A as the amount of necrotic tissue was a significant $18.1 \mathrm{~g}$ in experiment I and $30.2 \mathrm{~g}$ in experiment II higher. Thus, the ranking of genotypes did not differ from storage trials and was not affected by the site of cultivation (greenhouse or field). This was further confirmed as the invert sugar concentration in genotype B was 1.7 times higher than in genotype A in both experiments; although the total amount of invert sugar was generally higher in experiment I. Based on the biomass of $F$. graminearum determined by qPCR, genotype A was colonized to lesser extent (604.1 ng of DNA $\mathrm{g}^{-1}$ of FM) than genotype $\mathrm{B}$ (1039.8 $\mathrm{ng}$ of DNA $\mathrm{g}^{-1}$ of FM); however, due to the large standard deviation this difference was statistically not significant

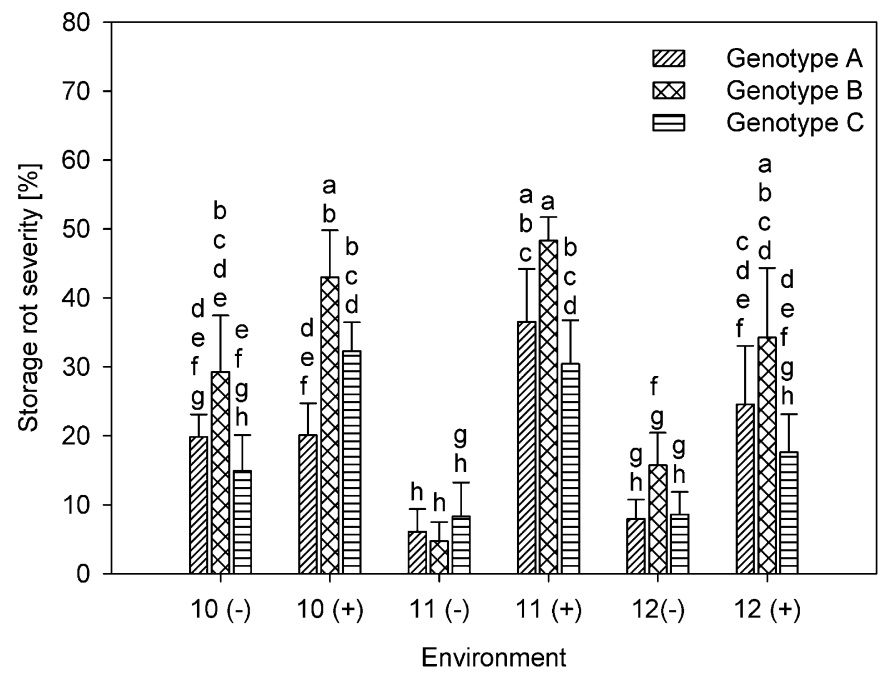

Fig. 2. Effect of environment (10 to 12 ) and genotype (A to C) on the percentage of discolored (rotted) tissue in the longitudinal cut of untreated sugar beets (-) and damaged (+) sugar beets after storage for 97 days under controlled conditions at $8^{\circ} \mathrm{C}($ trial $2013, n=6)$. Means with the same letter are not significantly different at $P<0.05$ according to Tukey's test. Error bars indicate standard deviation.
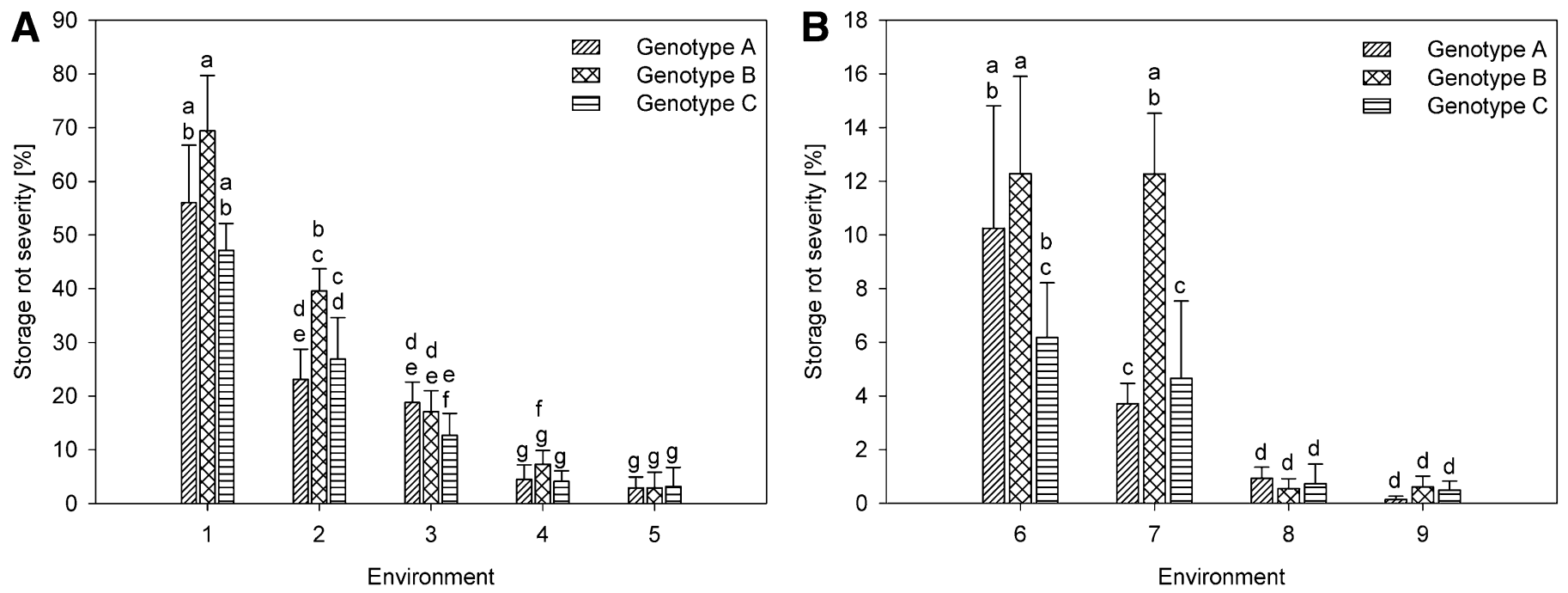

Fig. 1. Effect of environment (1 to 9) and genotype (A to C) on the percentage of discolored (rotted) tissue in the longitudinal cut of sugar beets after storage for 91 days $(\mathbf{A}$, trial 2011, $n=5)$ or 103 days $(\mathbf{B}$, trial 2012, $n=6)$ under controlled conditions at $8^{\circ} \mathrm{C}$. Means with the same letter are not significantly different at $P<0.05$ according to Tukey's test. Error bars indicate standard deviation. 
$(P=0.0546) . F$. graminearum was not detected in noninoculated roots of both genotypes (limit of detection $=7 \mathrm{pg}$ of fungal DNA $\mu \mathrm{l}^{-1}$ ).

Detection of storage pathogens. A microarray supplied with 42 oligonucleotide probes allowing a qualitative detection of important storage pathogens was applied to identify major species associated with storage rot development. For this purpose, sugar beets from two environments, displaying large differences in storage rot severity, were analyzed in each year. To identify changes in the species composition, reference samples taken before storage were also included in the analysis. Besides a species-specific detection, the microarray contained several group-specific probes targeting at least two species of the same genus. Therefore, results of these probes are indicated only by the genus name without mentioning a certain species (e.g., Colletotrichum sp.).

In total, 18 different species were identified in sugar beets before prior to storage (Table 4). The detection frequency for each species was calculated across all analyzed samples. In general, there was no obvious relation between species detected and the rot severity observed after storage. Species with the highest detection frequency were mostly detected in both samples of each treatment. Bacterial organisms were present in all samples indicated by a strong signal of a probe which also served as a positive control for hybridization. A probe targeting the genus Leuconostoc confirmed the presence of at least one species in nearly all samples $(91.6 \%)$. In all years, Colletotrichum represented the fungal genus most frequently detected in each genotype (83.3\%) except for sugar beets derived from environment 6 (2012). Apart from that, seven different Fusarium spp. were found in freshly harvest sugar beets. Predominant species were $F$. graminearum $(47.9 \%)$ and $F$. culmorum $(41.6 \%)$ followed by $F$. redolens, $F$. tricinctum, $F$. avenaceum, $F$. equiseti, and $F$. venenatum. The incidence of these species was generally higher in the years 2011 and 2012 than in 2013. Besides bacterial and fungal organisms, various oomycetes species including Aphanomyces cochlioides, Pythium aphanidermatum, $P$. deliense, P. intermedium, and P. ultimum were also present in sugar beets. After storage, the species composition had hardly changed but a clear increase of the detection frequency was observed for certain species (Table 5). In general, there was no obvious effect of genotype, environment and damage on the species detected in stored sugar beets. Moreover, Botrytis was the fungal genus most often $(100 \%)$ detected in both samples, independent of the storage rot severity. Comparable, positive signals of a group-specific probe
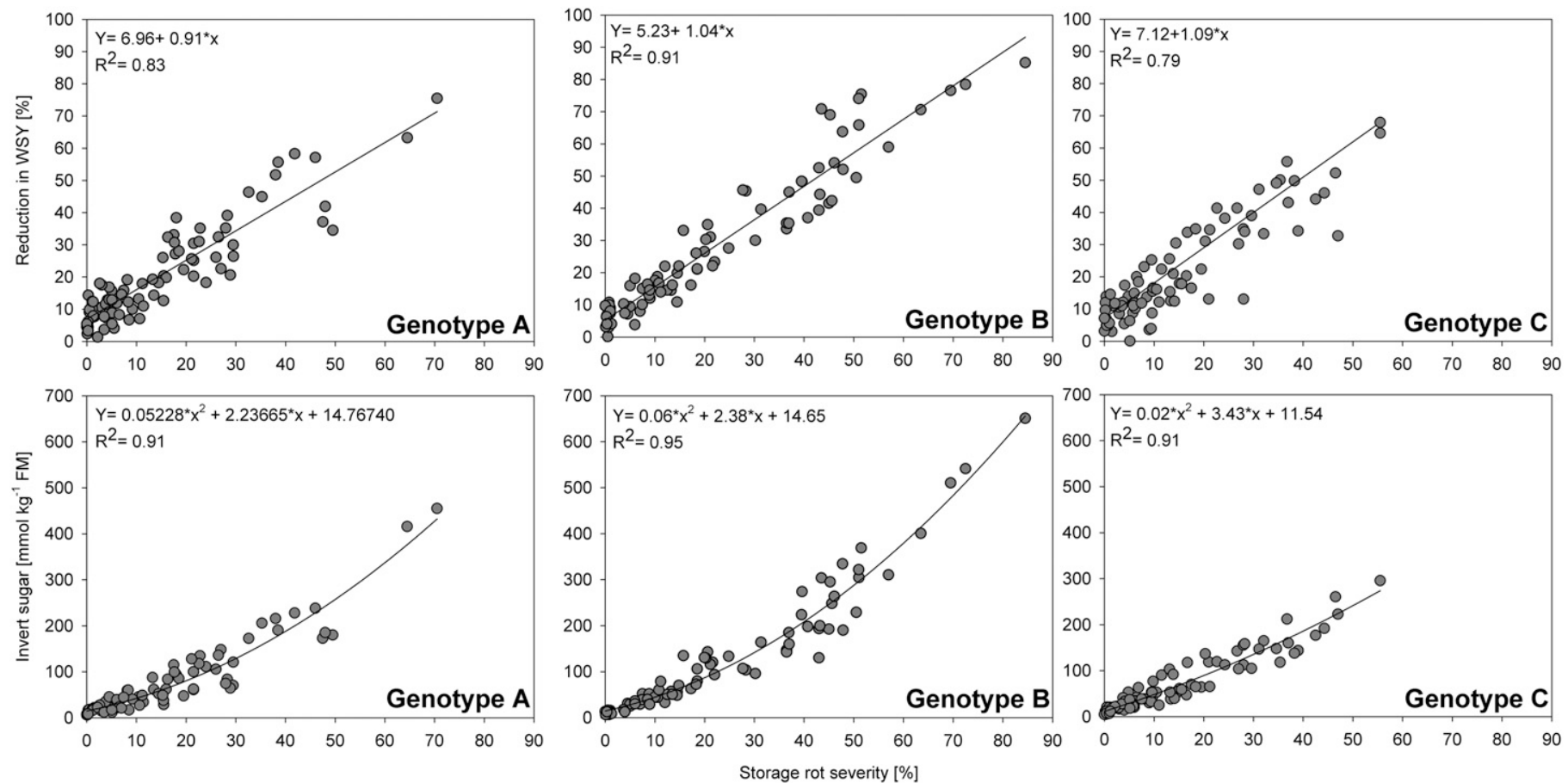

Fig. 3. Relationship between percentage of discolored (rotted) tissue in the longitudinal cut of stored sugar beets, reduction in white sugar yield (WSY) and invert sugar content (mmol kg-1 of fresh weight [FM]). Regression functions were estimated for each genotype (A to C) based on the data from trials conducted between 2011 and 2013. Samples subjected to a damage treatment in 2013 were excluded from analysis.

TABLE 3. Effect of genotype on necrotic tissue, invert sugar and fungal biomass of sugar beets inoculated with Fusarium graminearum ${ }^{\mathrm{a}}$

\begin{tabular}{|c|c|c|c|c|c|c|}
\hline \multirow[b]{2}{*}{ Experiments $^{\mathrm{b}}$} & \multicolumn{2}{|c|}{ Necrotic tissue $(\mathrm{g})$} & \multicolumn{2}{|c|}{$\begin{array}{c}\text { Invert sugar } \\
\text { (mmol kg-1 of fresh matter) }\end{array}$} & \multicolumn{2}{|c|}{$\begin{array}{c}\text { Fungal biomass }^{\mathrm{c}} \\
\text { (ng of DNA } \mathrm{g}^{-1} \text { of fresh matter) }\end{array}$} \\
\hline & Inoculated & Noninoculated & Inoculated & Noninoculated & Inoculated & Noninoculated \\
\hline \multicolumn{7}{|l|}{ I } \\
\hline $\begin{array}{l}\text { Genotype B } \\
\text { II }\end{array}$ & $40.7 \mathrm{~b} \pm 13.5$ & 0 & $121.4 \mathrm{~b} \pm 66.5$ & $18.2 \pm 6.9$ & $1,039.8$ a $\pm 1,114.6$ & 0 \\
\hline Genotype A & $64.5 \mathrm{a} \pm 15.9$ & 0 & $31.8 \mathrm{a} \pm 15.8$ & $5.8 \pm 1.4$ & n.d. & n.d. \\
\hline
\end{tabular}

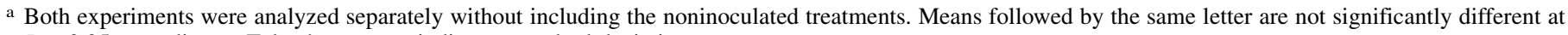
$P<0.05$ according to Tukey's test. $\pm x$ indicates standard deviation.

b Sugar beets were either grown in the greenhouse (experiment I) or in the field (experiment II).

c n.d. = not determined. 
for the genus Penicillium (83.33\%) indicated a strong colonization during storage since this genus remained undetectable in freshly harvested samples. For Fusarium spp., the total number of identified species remained unchanged but the detection frequency increased dramatically with the greatest increase for $F$. tricinctum (25 to $93.7 \%$ ) followed by $F$. avenaceum (12.5 to $66.6 \%$ ) and $F$. venenatum (10.4 to $50 \%)$. In contrast, the occurrence of Leuconostoc (91.6 to $18.7 \%$ ) and Colletotrichum (83.3 to $4.1 \%$ ) species considerably decreased after storage. Similarly, all oomycete species identified in freshly harvest sugar beets were occasionally found after storage but with a substantially lower detection frequency.

\section{DISCUSSION}

The occurrence of rots during sugar beet storage has often been described as erratic since phenotypically healthy harvested sugar beets could develop rot symptoms during storage (Campbell and Klotz 2007; Christ et al. 2011). This observation is confirmed by the present study as stored samples varied greatly in rot severity which has been demonstrated to depend largely upon the environment of cultivation followed by genotypic effects. However, the species spectrum colonizing stored sugar beets remained fairly constant across different environments and genotypes with dominant species belonging primarily to the fungal genera Botrytis, Fusarium, and Penicillium.

Bugbee and Cole (1986) observed an increase in the amount of storage rots (from 3 to 19\%) under controlled conditions depending on the position of the replicate in the field trial $\left(4.500 \mathrm{~m}^{2}\right)$. This evidence suggests that already small-scale environmental effects have an influence on the storage rot development. In this study, sugar beet field trials were located in far distance and performed by different institutions. Thus, abiotic conditions (e.g., climate, soil type), biotic conditions (e.g., disease pressure), agronomic practices (e.g., crop rotation, fertilizer), and harvest techniques were completely different. Hence environmental factors that could have caused the large variability are manifold. However, the importance of wounds for storage rot development has been clearly demonstrated by the damage treatment which increased rot severity remarkably. Various factors including type of harvester, harvesting speed and environmental conditions determine root damage during harvest. Thus it can be assumed that sugar beets from different environments suffered varying degrees of damage which in turn affected the rot development. However, sugar beets from environment 8 , although being mechanically harvested, did not show significant storage rot (on average $0.7 \%$ ) similar to hand-harvested beets from environments 5 (on average 3\%) and 9 (on average $0.4 \%$ ). This suggests that other factors also contributed to storage rot development. As all sugar beets were apparently healthy at harvest, a predisposition caused by plant diseases like $A$. cochlioides or Rhizoctonia crown and root rot on the storability can be excluded. Gaskill (1950a) reported that sugar beets displayed more storage rots when they were exposed to intensive drying conditions after harvest. Apart from that, the author suggested that drought stress also probably affects storage rot development. However, reliable data on environmental factors predisposing sugar beets to storage rots are missing; and therefore, must be further studied in systematic storage trials.

Genotypic effects on storage rot development have been revealed already many years ago (Gaskill 1950b, 1952b), but this is the first study investigating this effect across different environments with modern sugar beet hybrids. In all trials, genotype effects were

TABLE 4. Microorganism species detected in freshly harvested sugar beets of three genotypes cultivated at six locations

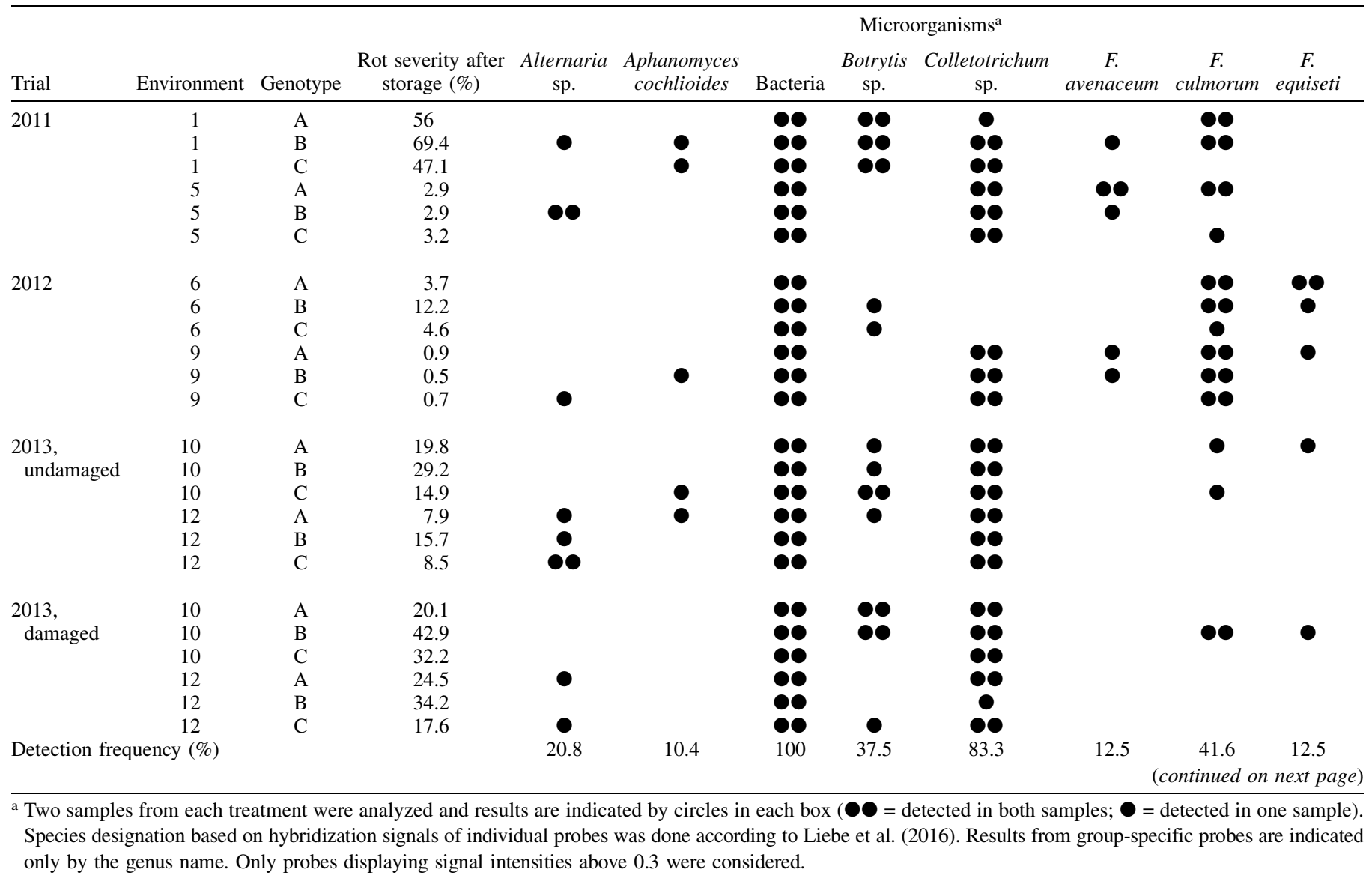


significant but characterized by an interaction with the environment due to a low incidence of storage rots in certain environments. A damage treatment prior to storage could circumvent this problem by increasing the rot severity leading to significant genotype differentiation in most environments. In accordance with previous studies (Gaskill 1950b, 1952b), the genetic resistance of the plants did not prevent infection but seems to delay the progress of the colonization process suggesting to be based on quantitative traits. Furthermore, it has been shown consistently in all trials that genotype B ranked first for rot severity. In contrast, ranking of genotypes $\mathrm{A}$ and $\mathrm{C}$ alternated but without statistical significance. Under high root rot pressure (environment 1 ), reduction in WSY for the genotypes A and C was $20 \%$ lower than for genotype B. Thus, improving genetic resistance through breeding will substantially contribute to a better storability of sugar beets. Until now, commercial hybrids with selected resistance traits against storage rots are not available. However, the results clearly demonstrate that modern sugar beet hybrids already possess remarkable genetic variability but the full genetic potential must be determined in further studies comprising a larger set of genotypes.

The development of storage rot has been shown to be erratic which complicates the identification of genotype effects. Thus expensive and laborious storage trials including many environments or at least a damage treatment prior to storage are required to guarantee rot development in a level sufficient to identify genotype effects. Therefore, a storage rot resistance assay was applied to prove the reproducibility of genotype effects observed in storage trials. In previous studies, genetic resistance was evaluated by measuring the rotten tissue either after inoculation of small tissue pieces (Bugbee 1979a,b; Gaskill 1952a) or intact sugar beets (Gaskill 1950b; Klotz Fugate et al. 2012). Based on these approaches, resistance has been identified against $B$. cinerea, $P$. betae, and $P$. vulpinum. However, most of the aforementioned studies did not validate their observations in storage trials. In this study, $F$. graminearum was selected for wound inoculation of intact beets as it represents a frequent colonizer of stored sugar beets in Europe (Christ et al. 2011). In addition to the above mentioned studies in which only the amount of rotten tissue was measured, here the invert sugar content and fungal biomass was analyzed in parallel. Consistently over all three measured parameters, the higher susceptibility of genotype B toward storage rots could be reproduced by inoculation with $F$. graminearum. In particular, the higher fungal biomass quantified by real-time PCR is characteristic for a greater proliferation rate and a different resistance level (De Coninck et al. 2012; Oliver et al. 2008). In accordance with storage trials, the ranking of genotypes was independent of the site of cultivation (greenhouse or field). These results corroborate previous findings (Gaskill 1950b) where a higher resistance against $P$. betae was correlated with a lower storage rot severity of noninoculated sugar beets in storage trials. In addition, Gaskill (1952b) showed that crossing of sugar beets selected through an inoculation assay improved storage rot resistance. However, the high correlation of results from storage and laboratory trials should be further confirmed with a larger set of genotypes. Additionally, future experiments must also prove whether the genetic resistance selected by $F$. graminearum is effective against other storage pathogens as well.

Although it is well known that storage rot development is strongly associated with sucrose losses and invert sugar accumulation (Bugbee and Cole 1976; Klotz and Finger 2004; Mumford and Wyse 1976; Van Swaaij and Huijbregts 2010), this effect and its relative contribution to the storability of sugar beets has been not

TABLE 4. (continued from preceding page)

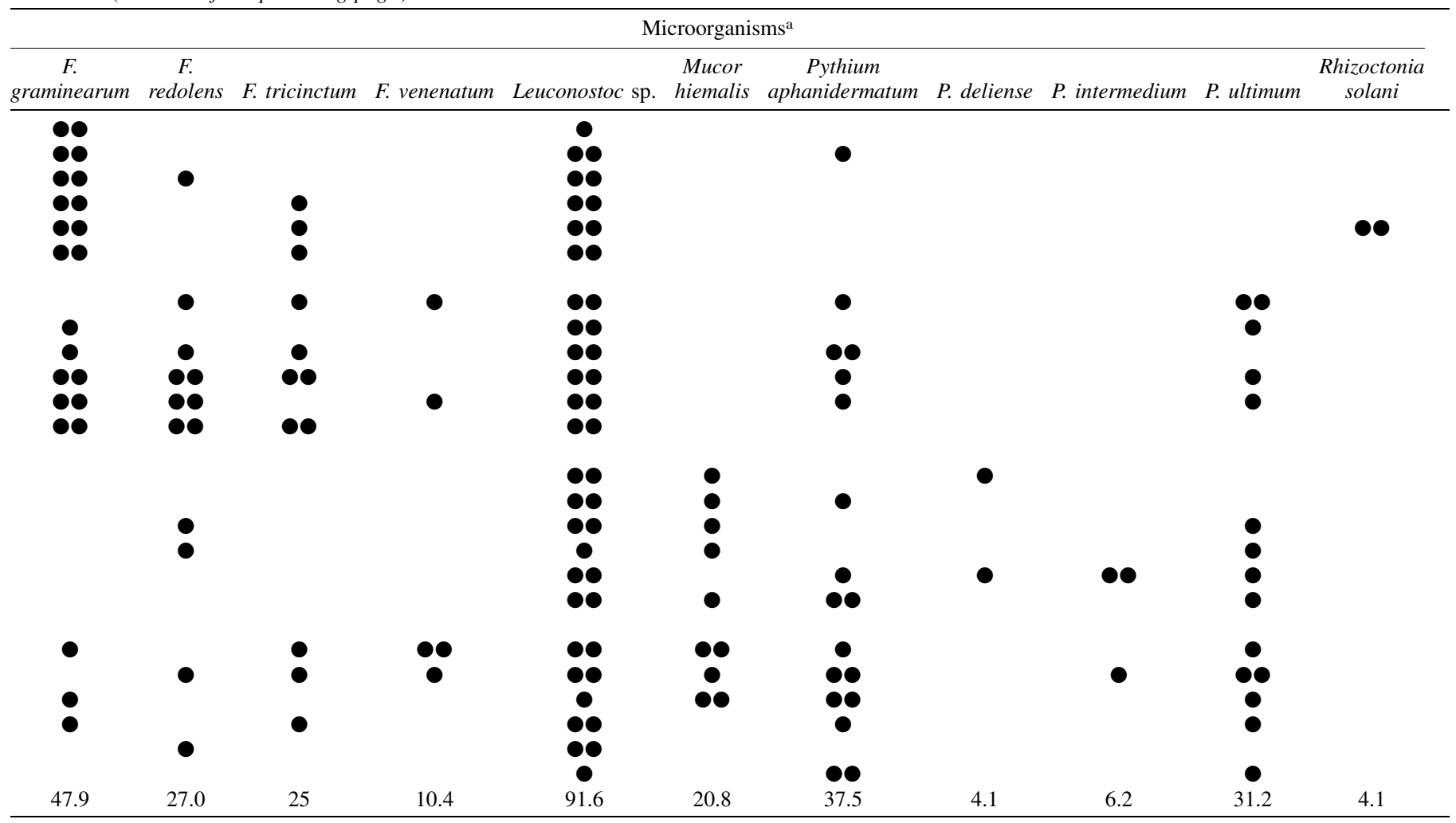


studied across different genotypes before. Based on regression analysis, it has been shown for all genotypes that changes in storability in terms of sucrose losses $\left(R^{2}=0.79\right.$ to 0.91$)$ and invert sugar accumulation $\left(R^{2}=0.91\right.$ to 0.95$)$ are primarily attributed to varying rot severity. This highlights the need of rot rating in storage trials to understand variation in sugar beet storability. Thus environment and genotype effects revealed in previous studies focusing only on sugar beet quality (Akeson and Widner 1981; Campbell and Klotz 2007; Cole 1977; Kenter and Hoffmann 2009; Van Swaaij and Huijbregts 2010; Wyse and Dexter 1971a,b) are at least partly attributed to a varying storage rot susceptibility. This is further corroborated by the fact that the estimated quality reduction in absence of storage rots indicated by the regression intercepts was very low with negligible differences between genotypes. Apart from that, the slopes hardly differed between genotypes indicating a similar yield-loss relationship. As the invert sugar content responded in a particularly sensitive way to rot development in both field and laboratory trials, it constitutes an ideal indicator for storage rots and could replace labor intensive rating. Clamp management could be improved by continuously measuring the invert sugar content in representative samples for early identification of beginning storage rot.

Until now, studies investigating the microbial colonization of sugar beets during storage used solely in vitro isolation and focused primarily on microorganisms present in rotten tissue (Bosch and Mirocha 1992; Bugbee and Cole 1976). In this study, both sugar beets with low and severe rot symptoms were analyzed to reveal differences in the species spectrum associated with increasing rot severity. Moreover, this is the first study applying molecular tools to identify predominant species across different environments and genotypes. Using this approach, a great diversity of microorganism species could already be identified in freshly harvested sugar beets, confirming the presence of an endophyte community in healthy appearing sugar beets described in previous studies (Christ et al. 2011; Shi et al. 2009). This community changed after storage toward a dominance of species from the fungal genera Botrytis, Fusarium, and Penicillium. This shift was observed consistently across different environments and genotypes which can be explained by the fact that all samples displayed at least a few rot symptoms. Although microarray based detection did not differentiate between viable and dead cells and allows no conclusion on pathogenicity, the sharp increase of the detection frequencies strongly indicates an intensive postharvest colonization. Considering the results of the storage rot resistance assay, differences in the biomass of storage pathogens in relation to rot severity can be expected, however, the microarray allows only qualitative detection of its targets. Some of these storage pathogens were identified only by group-specific probes targeting several species within one genus. Nevertheless, conclusions about species involved can still be drawn. For example, B. cinerea as the only polyphagous species within this genus infecting sugar beets (Staats et al. 2005) was identified in previous studies as a storage pathogen (Bugbee and Cole 1976; Klotz and Finger 2004). Thus, it is very likely that this species was detected in stored beets. Apart from that, at least one Penicillium species was present in most samples which corroborates results of previous studies (Bugbee and Cole 1976; Christ et al. 2011; Klotz and Finger 2004; Strausbaugh et al. 2015). However, further work is necessary to determine which species are involved since this probe was only specific on genus level. Within the Fusarium mycoflora, all species detected in this study are known as colonizers of stored

TABLE 5. Microorganism species detected in three sugar beet genotypes cultivated at six locations and stored at $8^{\circ} \mathrm{C}$ under controlled conditions for either 103 days (2011), 91 days (2012), or 97 days (2013)

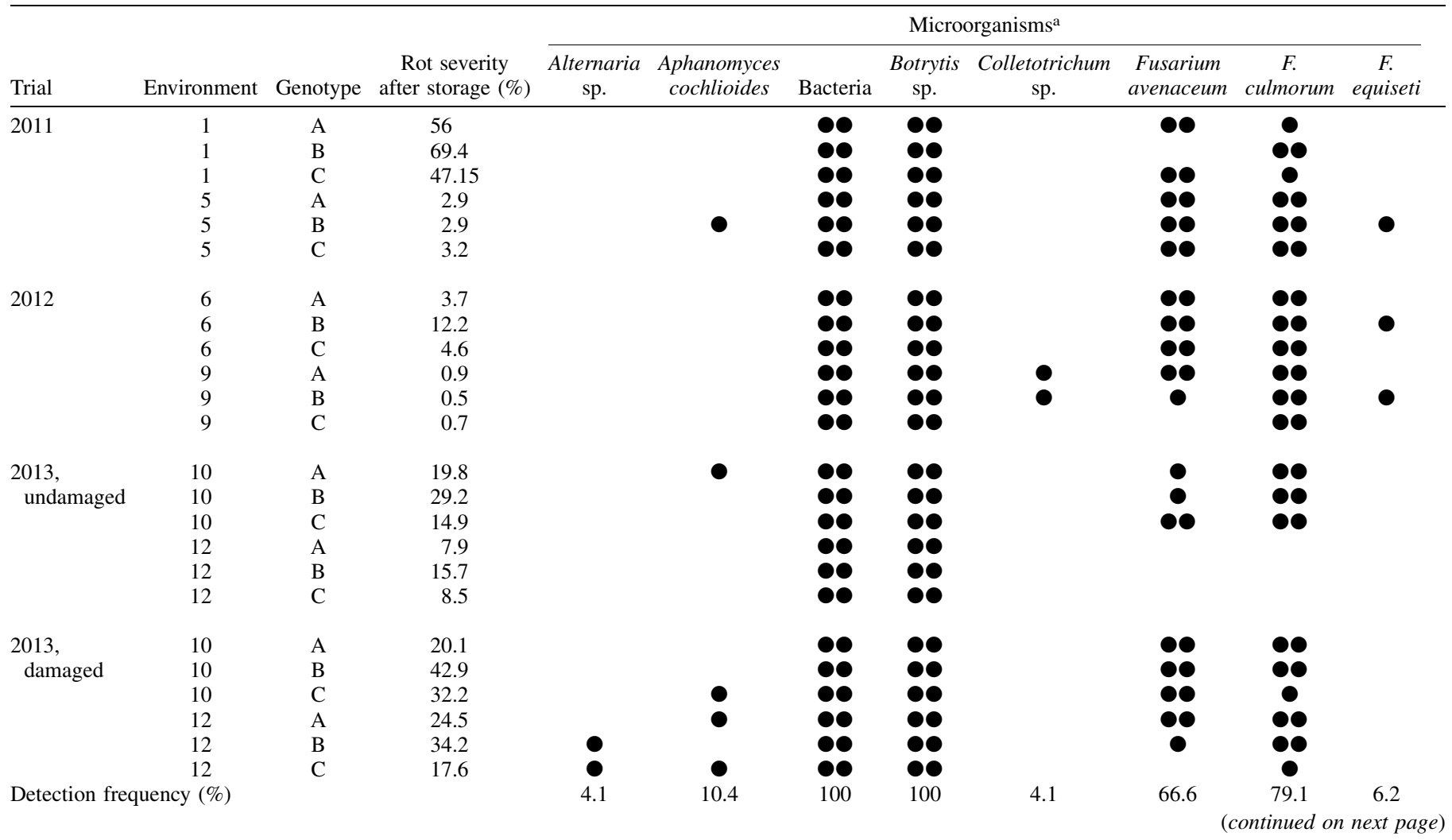

a Two samples from each treatment were analyzed and results are indicated by circles in each box $(\boldsymbol{\bullet}=$ detected in both samples; $\boldsymbol{\bullet}=$ detected in one sample $)$. Species designation based on hybridization signals of individual probes was done according to Liebe et al. (2016). Results from group-specific probes are indicated only by the genus name. Only probes displaying signal intensities above 0.3 were considered. 
sugar beets (Bosch and Mirocha 1992; Christ et. al 2011). Other important fungal species like $P$. vulpinum and $P$. betae reported as storage pathogens in the United States (Bugbee and Cole 1976) were not detected by their specific probes, and therefore seem to be of low relevance in Europe. Furthermore, the incidence of species belonging to the genera Alternaria and Pythium decreased confirming their low relevance as storage pathogens (Fugate and Campbell 2009).

The major species found in this study are well known as wound pathogens in many other crops and fruits subjected to storage (Prusky and Gullino 2010 and references therein). This strongly underlines the importance of injuries for postharvest colonization as already observed in storage trials. In particular, B. cinerea is widely distributed because of its ability to infect more than 235 host plants (Staats et al. 2005). Interestingly, this species was already found in healthy sugar beets prior to storage. In fruit storage, symptomless infection during the growing season plays an important role for postharvest disease development, an issue recently reviewed by Prusky et al. (2013). The period from host penetration to symptom appearance is described as quiescence and occurs when environmental conditions or host physiology favor penetration without active growth of the pathogen. It is assumed that pathogens switch to a necrotrophic lifestyle at a certain phase during fruit ripening and senescence. However, this has yet to be completely investigated for sugar beet. Apart from that, the species spectrum detected by the microarray comprises only storage pathogens identified in previous studies; unknown species are not covered by this approach. Furthermore, unfavorable storage conditions like oxygen depletion and high temperature also affect microbial colonization as it has been shown for bacterial organisms (Bugbee et al. 1975b; Cole and Bugbee
1976). A genus-specific probe frequently detected Leuconostoc in freshly harvested roots which confirms previous findings from Strausbaugh and Gillen $(2008,2009)$. During storage, this bacterial organism was less frequently detected indicating a lower prevalence. Since roots were stored at cool temperatures $\left(8^{\circ} \mathrm{C}\right)$ in this study, the growth of bacterial organism was probably slowed down or prevented. Thus, further investigations are required addressing the effects of higher storage temperatures on the bacterial community. For this purpose, next-generation sequencing technologies should be preferably applied as it is a proven method to analyze bacterial communities in sugar beets (Shi et al. 2014; Zachow et al. 2014).

Due to political changes in the European Union sugar regime, European sugar factories consider to prolong the storage campaign and to increase the amount of stored beets (Busse and Jerosch 2006; Kenter and Hoffmann 2009). Thus, the future importance of storage rots will increase. Apart from economical effects, predominant storage pathogens (e.g., Fusarium spp.) described in this study are well known as producers of mycotoxins which is an important issue because of its negative impact on human and animal health (Bennett and Klich 2003; Bosch and Mirocha 1992; D’Mello et al. 1999). However, the production of mycotoxins is influenced by several factors including disease severity, fungal biomass, strain and temperature (Burlakoti et al. 2007; Christ et al. 2011; Mogensen et al. 2009). Thus, no conclusions about the risk of contamination can be drawn from these results but at least they indicate the need for further research to develop disease management strategies. Considering the results of the present study, this can be achieved by (i) understanding environmental factors predisposing sugar beets to storage rots, (ii) reducing harvest injuries, and (iii) improving genetic resistance.

TABLE 5. (continued from preceding page)

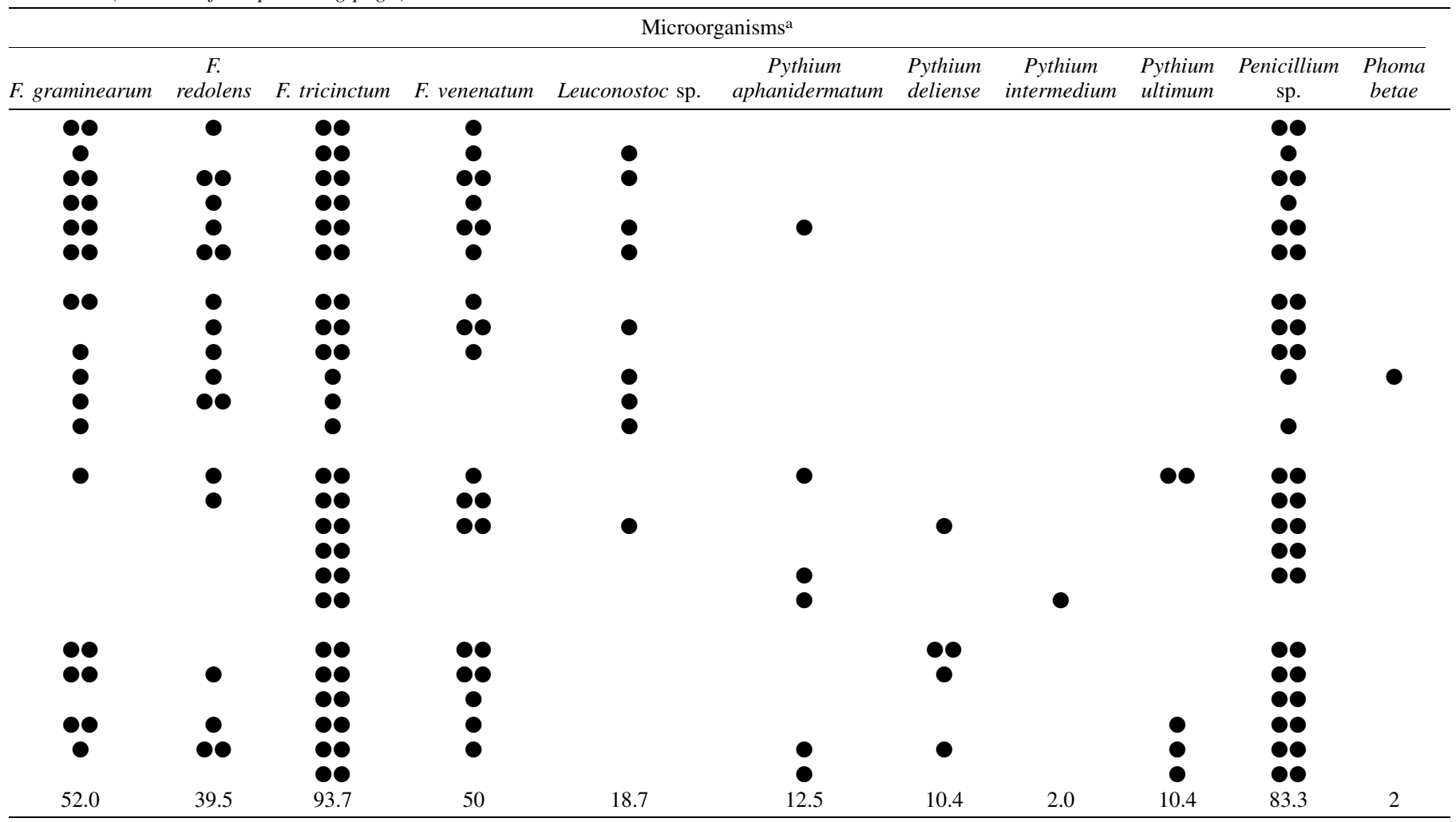




\section{ACKNOWLEDGMENTS}

The cooperative industrial research (IGF) project (17290 N/1) of the German Federation of Private Plant Breeders (GFP) was financed by the German Federal Ministry for Economic Affairs and Energy via the German Federation of Industrial Research Associations (AiF). We thank M. Stevens for critical reviewing of the manuscript.

\section{LITERATURE CITED}

Akeson, W. R., and Widner, J. N. 1981. Differences among sugarbeet cultivars in sucrose loss during storage. J. Sugar Beet Res. 21:80-91.

Bennett, J. W., and Klich, M. 2003. Mycotoxins. Clin. Microbiol. Rev. 16: 497-516.

Bosch, U., and Mirocha, C. J. 1992. Toxin production by Fusarium species from sugar beets and natural occurrence of zearalenone in beets and beet fibers. Appl. Environ. Microbiol. 58:3233-3239.

Brandfass, C., and Karlovsky, P. 2006. Simultaneous detection of Fusarium culmorum and $F$. graminearum in plant material by duplex PCR with melting curve analysis. BMC Microbiol. 6:4.

Buchholz, K., Märländer, B., Puke, H., Glattkowski, H., and Thielecke, K. 1995. Neubewertung des technischen Wertes von Zuckerrüben. Zuckerindustrie 120:113-121.

Bugbee, W. M. 1975. Penicillium claviforme and Penicillium variabile: Pathogens of stored sugar beets. Phytopathology 65:926-927.

Bugbee, W. M. 1979a. Resistance to sugar beet storage rot pathogens. Phytopathology 69:1250-1252.

Bugbee, W. M. 1979b. The effect of plant age, storage, moisture, and genotype on storage rot evaluation of sugarbeet. Phytopathology 69:414-416.

Bugbee, W. M. 1982. Storage rot of sugar beet. Plant Dis. 66:871-873.

Bugbee, W. M., and Cole, D. F. 1976. Sugarbeet storage rot in the Red River Valley 1974-75. J. Sugar Beet Res. 19:19-24.

Bugbee, W. M., and Cole, D. F. 1986. Sucrose content, clear juice purity and storage rot of sugarbeet. J. Sugar Beet Res. 23:154-165.

Bugbee, W. M., Cole, D. F., and Nielsen, G. 1975b. Microflora and invert sugars in juice from healthy tissue of stored sugarbeets. J. Appl. Microbiol. 29:780-781.

Burba, M., and Georgi, B. 1975. Die fluorometrische Bestimmung der Aminosäuren in Zuckerrüben und Zuckerfabriksprodukten mit Fluoreszamin und o-Phthalaldehyd. Zuckerindustrie. 25:667-673.

Burba, M., and Georgi, B. 1976. Die fluorometrische Bestimmung der Aminosäuren in Zuckerrüben und Zuckerfabriksprodukten mit Fluoreszamin und o-Phthalaldehyd. Zuckerindustrie. 26:322-329.

Burlakoti, R. R., Estrada, R., Jr., Rivera, V. V., Boddeda, A., Secor, G. A., and Adhikari, T. B. 2007. Real-time PCR quantification and mycotoxin production of Fusarium graminearum in wheat inoculated with isolates collected from potato, sugar beet, and wheat. Phytopathology 97:835-841.

Busse, M., and Jerosch, F. 2006. Reform of the EU sugar market. Inter. Econ. 41:104-107.

Campbell, L. G., and Klotz, K. L. 2007. Characterizing sugarbeet varieties for postharvest storage losses is complicated by environmental effects and genotype-environment interactions. Can. J. Plant Sci. 87:121-127.

Christ, D. S., Märländer, B., and Varrelmann, M. 2011. Characterization and mycotoxigenic potential of Fusarium species in freshly harvested and stored sugar beet in Europe. Phytopathology 101:1330-1337.

Cole, D. F. 1977. Effect of cultivar and mechanical damage on respiration and storability of sugarbeet roots. J. Sugar Beet Res. 19:240-245.

Cole, D. F., and Bugbee, W. M. 1976. Changes in resident bacteria, pH, sucrose, and invert sugar levels in sugarbeet roots during storage. Appl. Environ. Microbiol. 31:754-757.

D’Mello, J. P. F., Placinta, C. M., and MacDonald, A. M. C. 1999. Fusarium mycotoxins: A review of global implications for animal health, welfare and productivity. Anim. Feed Sci. Technol. 80:183-205.

De Coninck, B. M. A., Amand, O., Delauré, S. L., Lucas, S., Hias, N., Weyens, G., Mathys, J., De Bruyne, E., and Cammue, B. P. A. 2012. The use of digital image analysis and real-time PCR fine-tunes bioassays for quantification of Cercospora leaf spot disease in sugar beet breeding: Digital image analysis and real-time PCR to quantify CLS. Plant Pathol. 61:76-84.

Fugate, K., and Campbell, L. 2009. Part III. Postharvest deterioration of sugar beet. Pages 92-94 in: Compendium of Beet Diseases and Pests. 2nd ed. R. M. Harveson, L. E. Hanson, and G. L. Hein, eds. The American Phytopathological Society, St. Paul, MN.

Gaskill, J. O. 1950a. Effects of wilting, drought and temperature upon rotting of sugar beets during storage. Proc. Am. Soc. Sugar Beet Technol. 6:653-659.

Gaskill, J. O. 1950b. Possibilities for improving storage-rot resistance of sugar beets through breeding. Proc. Am. Soc. Sugar Beet Technol. 6:654-669.

Gaskill, J. O. 1950c. Progress report on the effects of nutrition, bruising, and washing upon rotting of stored sugar beets. Proc. Am. Soc. Sugar Beet Technol. 6:680-685.
Gaskill, J. O. 1952a. A study of two methods of testing individual sugar beet roots for resistance to storage pathogens. Proc. Am. Soc. Sugar Beet Technol. 7:575-581.

Gaskill, J. O. 1952b. Progress report on breeding for storage-rot resistance in sugar beets. Proc. Am. Soc. Sugar Beet Technol. 7:396-399.

Hoffmann, C. M. 2010. Root quality of sugarbeet. Sugar Technol. Rev. 12: 276-287.

International Commission for Uniform Methods of Sugar Analysis. 2007. Methods Book 2007. Verlag Dr. Albert Bartens KG, Berlin.

Jaggard, K. W., Clark, C. J. A., May, M. J., McCullagh, S., and Draycott, A. P. 1997. Changes in the weight and quality of sugarbeet (Beta vulgaris) roots in storage clamps on farms. J. Agric. Sci. 129:287-301.

Kenter, C., and Hoffmann, C. M. 2009. Changes in the processing quality of sugar beet (Beta vulgaris L.) during long-term storage under controlled conditions. Int. J. Food Sci. Technol. 44:910-917.

Kenter, C., Hoffmann, C., and Maerlaender, B. 2006. Optimierung der Rohstoffqualität von Zuckerrüben durch verbessertes Lagerungsmanagement. Zuckerindustrie 131:706-720.

Kenward, M. G., and Roger, J. H. 1997. Small sample inference for fixed effects from restricted maximum likelihood. Biometrics 53:983-997.

Klotz, K. L., and Finger, F. L. 2004. Impact of temperature, length of storage and postharvest disease on sucrose catabolism in sugarbeet. Postharvest Biol. Technol. 34:1-9.

Klotz Fugate, K., Ferrareze, J. P., Bolton, M. D., Deckard, E. L., and Campbell, L. G. 2012. Postharvest jasmonic acid treatment of sugarbeet roots reduces rot due to Botrytis cinerea, Penicillium claviforme, and Phoma betae. Postharvest Biol. Technol. 65:1-4.

Liebe, S., Christ, D. S., Ehricht, R., and Varrelmann, M. 2016. Development of a DNA microarray-based assay for the detection of sugar beet root rot pathogens. Phytopathology 106:76-86.

Mogensen, J. M., Nielsen, K. F., Samson, R. A., Frisvad, J. C., and Thrane, U. 2009. Effect of temperature and water activity on the production of fumonisins by Aspergillus niger and different Fusarium species. BMC Microbiol. 9:281.

Mumford, D. E., and Wyse, R. E. 1976. Effect of fungus infection on respiration and Reducing sugar accumulation of sugarbeet roots and use of fungicides to reduce infection. J. Sugar Beet Res. 19:157-161.

Nelson, N. 1944. A photometric adaptation of the Somogyi method for the determination of glucose. J. Biol. Chem. 153:375-380.

Nicholson, P., Simpson, D., Weston, G., Rezanoor, H., Lees, A., Parry, D., and Joyce, D. 1998. Detection and quantification of Fusarium culmorum and Fusarium graminearum in cereals using PCR assays. Physiol. Mol. Plant Pathol. 53:17-37.

Oliver, R. P., Rybak, K., Shankar, M., Loughman, R., Harry, N., and Solomon, P. S. 2008. Quantitative disease resistance assessment by real-time PCR using the Stagonospora nodorum-wheat pathosystem as a model. Plant Pathol. 57:527-532.

Prusky, D., Alkan, N., Mengiste, T., and Fluhr, R. 2013. Quiescent and necrotrophic lifestyle choice during postharvest disease development. Annu. Rev. Phytopathol.51:155-176.

Prusky, D., and Gullino, M. L. (eds.) 2010. Post-Harvest Pathology. Springer, New York

Roe, J. H. 1934. A colorimetric method for the determination of fructose in blood and urine. J. Biol. Chem. 107:15-22.

Saxton, A. M. 1998. A macro for converting mean separation output to letter groupings in Proc Mixed. Pages 1243-1246 in: Proc. $23^{\text {rd }}$ SAS Users Group Intl., SAS Institute, Cary, NC.

Shi, Y., Lou, K., and Li, C. 2009. Isolation, quantity distribution and characterization of endophytic microorganisms within sugar beet. Afr. J. Biotechnol. 8:835-840.

Shi, Y., Yang, H., Zhang, T., Sun, J., and Lou, K. 2014. Illumina-based analysis of endophytic bacterial diversity and space-time dynamics in sugar beet on the north slope of Tianshan mountain. Appl. Microbiol. Biotechnol. 98: 6375-6385.

Somogyi, M. 1945. A new reagent for the determination of sugars. J. Biol. Chem. 160:61-68.

Staats, M., Van Baarlen, P., and Van Kan, J. A. L. 2005. Molecular phylogeny of the plant pathogenic genus Botrytis and the evolution of host specificity. Mol. Biol. Evol. 22:333-346.

Strausbaugh, C. A., and Gillen, A. M. 2008. Bacteria and yeast associated with sugar beet root rot at harvest in the Intermountain West. Plant Dis. 92:357.

Strausbaugh, C. A., and Gillen, A. M. 2009. Sugar beet root rot at harvest in the US Intermountain West. Can. J. Plant Pathol. 31:232-240.

Strausbaugh, C. A., Neher, O., Rearick, E., and Eujayl, I. A. 2015. Influence of harvest timing, fungicides, and Beet necrotic yellow vein virus on sugar beet storage. Plant Dis. 10:1296-1309.

Strausbaugh, C. A., Rearick, E., Eujayl, I., and Foote, P. 2011. Influence of Rhizoctonia-bacterial root rot complex in storability of sugarbeet. J. Sugar Beet Res. 48:155-180. 
Tallgren, A. H., Airaksinen, U., von Weissenberg, R., Ojamo, H., Kuusisto, J., and Leisola, M. 1999. Exopolysaccharide-producing bacteria from sugar beets. Appl. Environ. Microbiol. 65:862-864.

Van Swaaij, N., and Huijbregts, T. 2010. Long-term storability of different sugarbeet genotypes-Results of a joint IIRB study. Zuckerindustrie 135:661-667.

Wyse, R. E. 1978a. Effect of harvest injury on respiration and sucrose loss in sugarbeet roots during storage. J. Sugar Beet Res. 20:193-202.

Wyse, R. E. 1978b. Effect of low and fluctuating temperatures on the storage life of sugarbeets. J. Sugar Beet Res. 20:33-42.
Wyse, R. E., and Dexter, S. T. 1971a. Effect of agronomic and storage practices on raffinose, reducing sugar, and amino acid content of sugarbeet varieties. J. Sugar Beet Res. 16:369-383.

Wyse, R. E., and Dexter, S. T. 1971b. Source of recoverable sugar losses in several sugarbeet varieties during storage. J. Sugar Beet Res. 16:390398.

Zachow, C., Müller, H., Tilcher, R., and Berg, G. 2014. Differences between the rhizosphere microbiome of Beta vulgaris ssp. maritima-ancestor of all beet crops-and modern sugar beets. Front. Microbiol. 5:415. 